\title{
Effect of Sigma Phase Precipitation on the Pitting Corrosion Mechanism of Duplex Stainless Steels
}

\author{
Wang Yongqiang ${ }^{1}$, Sun Hao ${ }^{1}, \mathrm{Li} \mathrm{Na}^{2 *}$, Xiong Yanhao ${ }^{1}$, Jing Hemin ${ }^{1}$ \\ ${ }^{1}$ School of Materials Science and Engineering, Anhui University of Technology, Maanshan, Anhui, \\ 243002, China \\ ${ }^{2}$ School of Metallurgical Engineering, Anhui University of Technology, Maanshan, Anhui, 243002, \\ China \\ *Corresponding author, E-mail: linaustb@163.com
}

doi: $10.20964 / 2018.10 .38$

Received: 29 May 2018/ Accepted: 27 July 2018 / Published: 1 September 2018

\begin{abstract}
A new phenomenon of the pitting corrosion of three duplex stainless steels (DSSs), SAF2205, SAF2507 and Z3CN20.09M, induced by sigma phases is found and discussed. The pitting potential $\left(E_{p}\right)$ of all three DSS specimens with smaller variations in the level of Cr content is remarkably higher than that of specimens with larger variations in $\mathrm{Cr}$ content, although they contain almost the same sigma precipitates. Even if there is much sigma phase in specimens with smaller variations in $\mathrm{Cr}$ content, they still present more resistance to pitting corrosion by high $\mathrm{E}_{\mathrm{p}}$ values. The EIS results and microstructures of the DSS specimens after polarisation tests are in accordance with the potentiodynamic anodic polarisation results. The pitting of DSS induced by sigma precipitation is mainly ascribed to the level of difference in $\mathrm{Cr}$ content between the sigma phase and Cr-depleted zone and not only to the Cr-depleted zone itself.
\end{abstract}

Keywords:duplex stainless steel; sigma phase; Cr content difference; potentiodynamic polarisation; pitting corrosion

\section{$\underline{\text { FULL TEXT }}$}

(C) 2018 The Authors. Published by ESG (www.electrochemsci.org). This article is an open access article distributed under the terms and conditions of the Creative Commons Attribution license (http://creativecommons.org/licenses/by/4.0/). 